\title{
The transmethylation and one-carbon cycle hypotheses of schizophrenia ${ }^{1}$
}

The current literature contains a degree of confusion over the nature and origins of the transmethylation hypothesis of schizophrenia, partly occasioned by the fact that there are two quite different transmethylation hypotheses.

The first (TMH I) has been variously attributed to Osmond \& Smythies (see e.g. Kety, 1959; Gillin et al. 1976), to Osmond, Harley-Mason \& Smythies (see e.g. Smythies, 1967), and to Harley-Mason (see e.g. Smythies, 1960; Baldessarini et al. 1979). In the literature to date, 63 references for TMH I are given to Osmond \& Smythies, 10 to Osmond, Harley-Mason \& Smythies, and 6 to Harley-Mason. None of these is, however, correct. The facts of the matter are as follows. TMH I was the result of a single chain of observations and deductions carried out by four people, each of whose contribution was essential to the final formulation of the hypothesis as detailed in the following sequential time sequence:

(1) the observation that the molecule of mescaline appeared to resemble some familiar compound (Smythies);

(2) the identification of this compound with adrenaline (Redmill);

(3) the observation that the clinical syndrome produced in some individuals by mescaline closely resembles the clinical syndrome seen in certain acute cases of schizophrenia (Osmond \& Smythies);

(4) the hypothesis that schizophrenia might result from some abnormality of adrenaline metabolism with the production of mescaline-like compounds in the brain (Osmond \& Smythies);

(5) the biochemical details of how such a metabolic error might occur (Harley-Mason).

Clearly, in such a process, it would be invidious to refer to any other than all those cooperatively responsible as 'the author' of the TMH I. In order to make referencing as easy as possible, in view of the fact that the listed authors of this paper are Osmond \& Smythies, I would suggest that the correct attribution and reference for TMH I should be: Osmond, H., Smythies, J., Harley-Mason, J. \& Redmill, J. (1952). Schizophrenia: a new approach. Journal of Mental Science 98, 309-315.

The current relevance of TMH I does not lie in its 'correctness' for, of course, there is no evidence that schizophrenia is associated with the presence in the brain of mescaline-like compounds. Hallucinogens (methylated derivatives of tryptamine in the form of dimethyltryptamine (DMT), and $O$-methylbufotenin (OMB)) have been identified in human CSF and rat brain by definitive gas-chromatography/mass-spectrometry (GC/MS) methodology (Smythies et al. 1979), and in urine by GC methodology (Checkley et al. 1979), but the differences between schizophrenics and normal controls were only minor and much higher levels were seen in cases of liver disease without psychosis. Experiments by Harrison (1982) have shown that rat brain DMT and OMB levels are significantly increased by stress (pain, immobilization) and that this does not occur if the adrenals are removed, suggesting a physiological role related to stress rather than psychosis for these endogenous hallucinogens. Developmental studies by Beaton \& Morris (1982) have shown that rat brain DMT and OMB levels increase rapidly from birth to around the 17 th day and then decrease to low levels. Thus, DMT may have a significant role in the brain, but it does not appear to be directly related to the pathogenesis of schizophrenia.

The significance of TMH I arises $(a)$ because of the impetus it gave to the use of hallucinogens in psychiatric research, and $(b)$ because it presented the first formulation of the hypothesis that catecholamines might be $O$-methylated in the body, which adumbrated the later discovery of

\footnotetext{
1 Address for correspondence: Professor J. R. Smythies, School of Medicine, The Neurosciences Program, University of Alabama in Birmingham, University Station, Birmingham, Alabama 35294, USA.
} 
metanephrine and catechol- $O$-methyltransferase. It is noteworthy that the formula of the 4methoxy-3-hydroxy isomer of metanephrine was printed for the first time in our 1952 paper.

The second transmethylation hypothesis (TMH II) (which should now be called the 'one-carbon cycle' hypothesis to avoid confusion) suggests that the biochemical fault in one of the schizophrenias might lie in the biochemical mechanism itself of transmethylation - namely the one-carbon cycle, in which methionine, $S$-adenosylmethionine (SAM) and folic acid are involved - rather than any abnormally methylated products. This hypothesis was first put forward in 1966 (Smythies, 1966), as follows: "The removal and addition of methyl groups is an operation of fundamental importance to the organism, and any fault in it might be expected to have a serious effect on the activity of neurons.' The current evidence to support such a defective methylation system in schizophrenia is as follows:

(1) Some $40 \%$ of chronic schizophrenics react by developing an acute psychotic reaction to $20 \mathrm{G} /$ day of $L$-methionine. This reaction has been reported by ten groups with no reported failures to replicate, which makes it unique in the annals of schizophrenia research (see Cohen et al. 1974, for a review). In our study (Antun et al. 1971 a), we found that in most cases the psychosis closely resembled clinically a schizophrenic reaction. In three out of the twelve cases, the patients were clearly delirious initially for some 48 hours, but they then reverted to a schizophreniform psychosis. Unfortunately, we do not know how manic-depressives would respond to methionine, and not enough careful studies have been carried out in normals. Furthermore, the experiment needs to be repeated in schizophrenics using modern methods of monitoring clinical status. However, the important point is that some $40 \%$ of schizophrenics respond dramatically to methionine and $60 \%$ do not. It would seem, therefore, worthwhile to find out by what mechanism methionine induces this effect and in what other ways methionine-sensitive schizophrenics differ from methionineinsensitive schizophrenics.

(2) Ismail et al. (1978) showed that the $C^{14}$ labelled methyl group of methionine converts abnormally slowly to $\mathrm{C}^{14} \mathrm{O}_{2}$ in schizophrenic cells, suggesting a possible defect in the one-carbon cycle. One might naively suppose that, since methionine is the ultimate source of all the methyl groups used in transmethylation reactions, these clinical effects of methionine might be due to an overpromotion of transmethylation reactions. However, methionine (a) did not increase urine levels of methylated metabolites of catecholamines in humans in our study (Antun et al. 1971 b), and (b) did not increase SAM levels in human blood, had no effect on methylation of tritiated levadopa in rodent tissues, and actually decreased the production of DMT by rabbit lung, possibly due to end-product inhibition by homocysteine, a potent inhibitor of transmethylation reactions (Stramentinoli \& Baldessarini, 1978; Schatz et al. 1981; Baudry et al. 1973). Hence, it may well be that the 'methionine effect' in chronic schizophrenics might be due to a further inhibition of an already defective transmethylation system. This hypothesis can be tested by measuring both $(a) V_{\max }$ levels of MAT and SHMT (see below), and $(b)$ conversion rates of the $\mathrm{C}^{13}$ labelled methyl group of methionine to $\mathrm{C}^{13} \mathrm{O}_{2}$ using $\mathrm{GC} / \mathrm{MS}$ methodology in methionine-sensitive and methionineinsensitive schizophrenics.

(3) Kinetic analyses over a period of five years by our group (Carl et al. 1978; Kelsoe et al. 1982) have shown that the $V_{\max }$ of methionine adenosyltransferase (MAT) and serine hydroxymethyltransferase (SHMT) are significantly underactive in schizophrenics, whereas four other enzymes of the one-carbon cycle showed no changes. Moreover, the patients (except one) low in MAT activity were not those with low SHMT activity, indicating two possible subgroups. Preliminary results indicate that a low $V_{\max }$ activity for SAM is also seen in patients with major affective (depressed) patients, whereas manics show high values, suggesting a state rather than a trait change (Tolbert et al. 1983). An earlier observation by Sprince et al. (1965) is of interest. They showed that excess methionine intake in rats decreased urinary output of methylnicotinic acid and increased urinary indoleacetic acid excretion, due possibly to a block of methylation of nicotinic acid on the kynurenine pathway of tryptophan metabolism and a resultant augmentation of the rival pathway to tryptamine and indoleacetic acid.

It is also possible that endogenous $O$-methylated derivatives of catecholamines may have some physiological properties, as was first suggested by Smythies (1969) (rather than being inert excretory 
products, as is commonly supposed). Furgeson et al. (1976) have presented evidence that the dyskinesia, but not the stereotyped behaviour, induced by dopamine may actually be due to methoxy derivatives as it is abolished by inhibitors of catechol- $O$-methyltransferase. A link between the transmethylation and dopamine hypotheses is suggested by the report of Le Fur et al. (1981). They found that low doses of dopamine stimulate phospholipid methylation. They further state that incubation of mouse $B$-lymphocytes with $l$-methionine unmasks cryptic dopamine receptors - a response depending on phospholipid methylation.

Transmethylation reactions are now recognized to represent a widespread biochemical mechanism. Transmethylation of the carboxyl groups of proteins by carboxymethylases has been shown to affect neurotransmitter release and the chemotactic behaviour of Escherichia coli. In this organism a carboxymethylase has been shown to be a key factor in the development of habituation to chemical stimuli (Springer et al. 1979; Smythies, 1980). Chemical attractants increase methylation and decrease demethylation, whereas chemical repellants have the reverse effect (Toews et al. 1979; Kleene et al. 1979). Transmethylation of lipids has been shown to be an essential step in many membrane reactions, including coupling of adrenergic and other receptors to adenylate cyclase, histamine release by immunoglobulin $E$ antigens, nerve growth factor responses and others (Strittmatter et al. 1979). Transmethylation of histones, DNA and RNA play an important role in gene expression, DNA repair, mutation, DNA replication and recombination (Doerfler, 1981; Cato \& Burdon, 1979). Thus, a defect in methylation even at the kinetic level might have widespread effects on brain and behaviour.

J. R. SMYTHIES

\section{REFERENCES}

Antun, F., Burnett, G. B., Cooper, A. J., Daly, R. J., Smythies, J. R. \& Zeally, A. K. (1971 a). The effects of $l$-methionine (without MAOI) in schizophrenia. Journal of Psychiatric Research 8, 63-71.

Antun, F., Eccleston, D. \& Smythies, J. R. (1971 b). Transmethylation processes in schizophrenia. In Brain Chemistry and Mental Disease (ed. B. T. Ho and W. M. McIsaac), pp. 61-71. Plenum: New York.

Baldessarini, R. J., Stramentinoli, G. \& Lipikski, J. F. (1979). Methylation hypothesis. Archives of General Psychiatry 36, 303-307.

Baudry, M., Chast, F. \& Schwartz, J. C. (1973). Studies on $S$-adenosyl-homocysteine inhibition of histamine transmethylation in brain. Journal of Neurochemistry 20, 13-21.

Beaton, J. \& Morris, P. E. (1982). Developmental changes in the levels of $N, N$-dimethyltryptamine and related indolealkylamines in rat brain. Abstract, Society of Neuroscience.

Carl, G. F., Crews, E. L., Carmichael, S. M., Benesh, F. L. \& Smythies, J. R. (1978). Four enzymes of one-carbon metabolism in blood cells of schizophrenics. Biological Psychiatry 13, 773-776.

Cato, A. C. B. \& Burdon, R. H. (1979). Mammalian DNA methylation and a nuclear $S$-adenosyl $L$-methionine-dependent nuclease activity. Federation of European Biochemical Societies Letters 99, 33-38.

Checkley, S. A., Oon, M. C. H., Rodnight, R., Murphy, M. P., Williams, R.S. \& Birley, J. L. T. (1979). Urinary excretion of dimethyltryptamine in liver disease. American Journal of Psychiatry 136, 439-441.

Cohen, S., Nichols, A. \& Wyatt, R. (1974). The administration of methionine to chronic schizophrenic patients: a review of ten studies. Biological Psychiatry 8, 109-221.

Doerfler, W. (1981). DNA methylation-a regulatory signal in eukarytic gene expression. Journal of General Virology 57, 1-20.

Furgeson, M. D., Dill, R. E. \& Dorris, R. L. (1976). Importance of $O$-methylation in dopamine-induced motor and behavioural phenomena. Brain Research 105, 163-167.

Gillin, J. C., Kaplan, J., Stillman, R. \& Wyatt, R. J. (1976). The psychedelic model of schizophrenia : the case of $N, N$-dimethyltryptamine. American Journal of Psychiatry 133, 203-298.

Harrison, R. (1982). Stress elevation of brain and adrenal levels of non-polar tryptophan metabolites. Ph.D. Thesis: University of Alabama.
Ismail, L., Sargent, T.III, Dobson, E. L. \& Pollycove, M. (1978). Altered metabolism of the methionine methyl group in the leukocytes of patients with schizophrenia. Biological Psychiatry 13, 649-660.

Kelsoe, J. R. Jr, Tolbert, L. C., Crews, E. L. \& Smythies, J. R. (1982). Kinetic evidence for decreased methionine adenosyltransferase activity in erythrocytes from schizophrenics. Journal of Neuroscience Research 8, 99-103.

Kety, S. S. (1959). Biochemical theories of schizophrenia. Science 129, 1528-1532, 1590-1596.

Kleene, S. J., Hobson, C. \& Adler, J. (1979). Attractants and repellants influence methylation and demethylation of methylaccepting chemotaxis proteins in an extract of Escherichia coli. Proceedings of the National Academy of Sciences, USA 76, 6309-6313.

Le Fur, G., Phau, T., Canton, T., Tur, C. \& Uzar, A. (1981). Evidence for a coupling between dopaminergic receptors and phospholipid methylation in mouse B. lymphocytes. Life Sciences 29, 2737-2749.

Schatz, R. A., Wilens, T. E. \& Sellinger, O. Z. (1981). Decreased transmethylation of biogenic amines after in vivo elevation of brain $S$-adenosyl- $L$-homocysteine. Journal of Neurochemistry 36, 1739-1748.

Smythies, J. R. (1960). Recent advances in the biochemistry of psychosis. Lancet ii, 1287-1289.

Smythies, J. R. (1966). Recent advances in the biochemistry of schizophrenia. Guy's Gazette May 14, 2-7.

Smythies, J. R. (1967). Biochemical abnormalities associated with schizophrenia. Hospital Medicine April, 573-577.

Smythies, J. R. (1969). Neurochemical aspects of information processing in the brain. Communications in Behavioral Biology 3, 241-256.

Smythies, J. R. (1980). Brain protein carboxymethylases and schizophrenia. Psychoneuroendocrinology 5, 177-178.

Smythies, J. R., Morin, R. D. \& Brown, G. B. (1979). Identification of dimethyltryptamine and $O$-methylbufotenin in human cerebrospinal fluid by combined gas chromatography/mass spectrometry. Biological Psychiatry 14, 549-556.

Sprince, H., Parker, C. M., Jameson, D. \& Josephs, J. A. Jr (1965). Effect of methionine on nicotinic acid and indoleacetic acid 
pathways of tryptophan metabolism in vivo. Proceedings of the Society for Experimental Biology and Medicine 119, 942-946.

Springer, M. S., Goy, M. F. \& Adler, J. (1979). Protein methylation in behavioral control mechanisms and in signal transduction. Nature 180, 279-284.

Stramentinoli, G. \& Baldessarini, R. J. (1978). Lack of enhancement of dimethyltryptamine formation in rat brain and rabbit lung in vivo by methionine or $S$-adenosylmethionine. Journal of Neurochemistry 31, 1015-1020.

Strittmatter, W. J., Hirata, F. \& Axelrod, J. (1979). Phospholipid methylation unmasks cryptic beta-adrenergic receptors in rat reticulocytes. Science 204, 1205-1207.

Toews, M. L., Goy, M. F., Springer, M. S. \& Adler, J. (1979). Attractants and repellants control demethylation of methylated chemotaxis proteins in Escherichia coli. Proceedings of the National Academy of Sciences, USA 76, 5544-5548.

Tolbert, L., Monti, J., O'Shields, H., Walter-Ryan, W., Meadows, D. \& Smythies, J. R. (1983). Defective transmethylation and membrane lipids in schizophrenia. Psychopharmacology Bulletin (in the press). 